\title{
Reliability of caspase activity as a biomarker of hepatic apoptosis in nonalcoholic fatty liver disease
} A letter in response to: Yilmaz Y, Kurt R, Kalayci C. Apoptosis in nonalcoholic
steatohepatitis with normal aminotransferase values: zooming in on
cytokeratin 18 fragments. Biomarkers Med. 4(5), 743-745 (2010).

\section{KEYWORDS: apoptosis $\approx$ caspase $\approx$ CK18 $\approx$ M30 antigen $\approx$ nonalcoholic fatty liver disease - tissue polypeptide-specific antigen}

Apoptosis is definitely an important cause of liver cell death in most cases of liver injury [1]. Recent studies have suggested that increased hepatocyte apoptosis has an important role in progression from simple steatosis to nonalcoholic steatohepatitis (NASH) [2]. We appreciate the interest of Yilmaz et al. in our study and their comments regarding the methods used for detecting the apoptosis in nonalcoholic fatty liver disease (NAFLD) patients.

Most of the morphological changes of apoptotic cells are due to caspases, a group of cysteine proteases, which cleave substrates following their aspartic acid residues [3]. CK18 is a cytoplasmic intermediate filament protein that represents approximately $5 \%$ of total protein in hepatocytes, epithelial cells and tissue of epithelial origin [4]. CK18 is cleaved at two positions (Asp238 and Asp396) by caspases. Cleavage at the C-terminal domain 396 leads to formation of CK18-Asp396 neoepitope, also know as M30 antigen [5]. It has been shown that serum M30 antigen levels independently predict apoptosis in NASH [6]. Liver biopsy is an invasive and costly procedure. Moreover, given the extremely high prevalence of NAFLD in the general population, serum M30 antigen level is expected to become an ideal noninvasive biomarker for NASH, although it is not routinely available as a laboratory test.

However, there are some interrogations concerning the availability of M30 antigen for the early detection of apoptosis, because M30 antigen is stable during proteolysis and is released into the serum after plasma disintegration at later stages of apoptosis [7]. On the other hand, caspases are needed for the processing of M30 antigen and have been shown to be suitable markers for detecting very early signs of liver damage [8].
The tenor of the comments of Yilmaz et al. leads us to assume that they prefer to use M30 antigen as a noninvasive marker of apoptosis. However, in tissue sections of NASH series, detection of M30 antigen and caspase-3 level revealed a higher percentage of activated caspase-3-positive cells than M30 antigen-positive ones [9]. This may reflect the fact that there are many other substrates besides CK18 for caspase- 3 in apoptosis [10]. Therefore, in keeping a more sensitive approach for detecting apoptosis in tissue sections, we preferred to perform immunostaining for activated caspase- 3 instead of M30 antigen.

As Yilmaz et al. pointed out, the liver expression of caspase- 9 and -8 initiates and executes hepatocyte apoptosis by various routes in NAFLD. Apoptosis can be initiated by two types of signals: the intrinsic mitochondrial pathway (stimulated by cellular oxidative stress) and the extrinsic death receptor pathway (stimulated through a death receptor [TNFR or Fas]-mediated process) [2]. Both pathways are suspected to be involved in the pathogenesis of NASH [11,12]. The increased release of free fatty acids (FFA) from adipose tissue leads to insulin resistance and the transcription of TNF- $\alpha$. The increased delivery of TNF- $\alpha$ to the liver increases the generation of reactive oxygen species during $\beta$-oxidation of FFA. This oxidative stress and/or TNF- $\alpha$ induction sensitizes hepatocytes laden with fat to apoptotic cell death $[12,13]$. In the death receptor pathway, the initiator caspase- 8 is activated by the direct ligandmediated trimerization of TNFR-1 or Fas at the cell surface $[6,14]$. Irreparable genome damage, caused by oxidative stress, activates the intrinsic pathway, in which cytochrome $\mathrm{C}$ is released from the mitochondria and procaspase- 9 is activated in complex with Apaf-1 [14]. Both activated

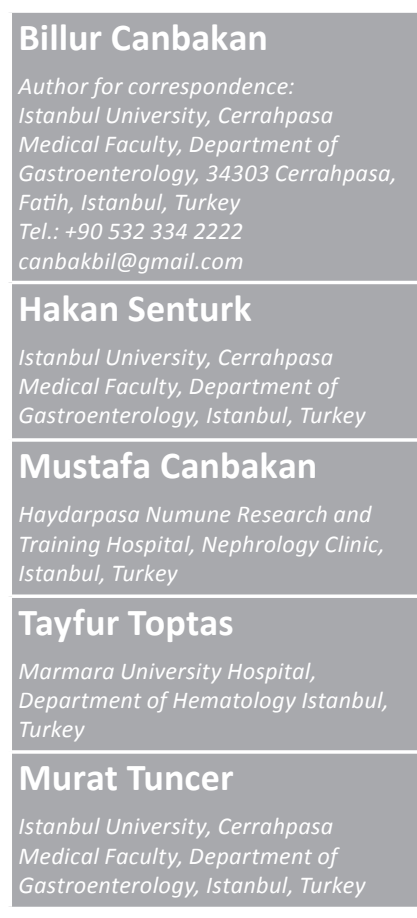

future medictio $^{\text {pisg }}$ fsg 
initiators, caspase- 8 in the death receptor pathway and caspase- 9 in the mitochondrial route, have been demonstrated to act on executioner procaspase- 3 and -7 [15]. Caspase- 8 and -9 can be thought of as initiators of pathways that converge at the execution phase of apoptosis. In this context, caspase- 3 and -7 might be considered as indicators of both pathways. However, MCF-7 cells deficient in caspase-3 failed to support processing of procaspase-9 [15]. This model predicts that deficiency of caspase-3 would affect mitochondrial apoptosis that has been triggered by caspase-9 activation. Therefore, caspase- 3 can be used as an indirect indicator of the mitochondrial pathway.

Cleavage of CK18 is mediated by caspase-3, -7 and -9 , and cleavage at the C-terminal domain 396 leads to formation of M30 antigen [5]. The determination of caspase-3- or -7-generated M30 antigen levels independently predicts both routes of apoptosis, since caspase- 3 and -7 are activated by initiator caspases of both pathways. Only caspase- 8 would serve as a specific indicator of the extrinsic pathway.

In keeping the activation of both apoptosis pathways in NAFLD in mind, we sought to determine caspase- 8 as an initiator caspase of the death receptor pathway and caspase- 3 as an indirect indicator of the mitochondrial pathway, because processing of procaspase- 9 requires the presence and activation of caspase-3 [15].

NAFLD encompasses simple fatty liver with a benign clinical course and NASH, which is a potentially serious condition with risk of cirrhosis and hepatocellular carcinoma. A definitive diagnosis of NASH still requires a liver biopsy. The increase of obesity and metabolic syndrome has caused a striking increase in NAFLD, and an urgent need to find noninvasive markers for the assessment of NASH. Among the various studied markers, tissue polypeptide-specific antigen (TPS) seems to be suitable for both screening and monitoring purposes in NAFLD [16]. TPS is a serological mirror of CK18, which provides mechanical stability to hepatocytes. TPS is released abundantly into the extracellular space during apoptosis and necrosis. $\mathrm{NASH}$ is characterized by cellular apoptosis and/or necrosis, which induce a repairing program with cellular regeneration, all leading together to a rise in TPS levels [17]. Tarantino et al. demonstrated that TPS is a better noninvasive marker than alanine aminotransferase activity, ultrasonography, or the two combined, in differentiating NASH from fatty liver [17]. The same research group validated the clinical utility of TPS in the monitoring of weightreduction programs, especially in the follow-up of overweight/obese patients with NASH [18]. The use of TPS exceeds the reliability of CK18 and its fragments in determining NASH. M30 antibody recognizes a caspase cleaved fragment of CK18 during apoptosis and M65 antibody measures the pool of uncleaved CK18 during necrosis. However, assessment of TPS level can not only be used to examine both of these different cell death modes - apoptosis and necrosis - but also to measure the compensative reparative response of the liver [17].

Financial \& competing interests disclosure

The authors have no relevant affiliations or financial involvement with any organization or entity with a financial interest in or financial conflict with the subject matter or materials discussed in the manuscript. This includes employment, consultancies, honoraria, stock ownership or options, expert testimony, grants or patents received or pending, or royalties.

No writing assistance was utilized in the production of this manuscript.

\section{References}

1 Malhi H, Gores GJ, Lemasters JJ. Apoptosis and necrosis in the liver: a tale of two deaths? Hepatology 43, S31-S44 (2006).

2 Wieckowska A, Zein NN, Yerian LM, Lopez AR, McCullough AJ, Feldstein AE. In vivo assessment of liver cell apoptosis as a novel biomarker of disease severity in nonalcoholic fatty liver disease. Hepatology 44, 27-33 (2006).

3 Cohen GM. Caspases: the executioners of apoptosis. Biochem. J. 326, 1-16 (1997).

4 Omary MB, Ku NO, Toivola DM. Keratins: guardians of the liver. Hepatology 35, 251-257 (2002).
5 Linder S, Havelka AM, Ueno T, Shoshan MC. Determining tumor apoptosis and necrosis in patient serum using cytokeratin 18 as a biomarker. Cancer Lett. 214, 1-9 (2004).

6 Yang X, Chang HY, Baltimore D. Autoproteolytic activation of pro-caspases by oligomerization. Mol. Cell. 1, 319-325 (1998).

7 Bivén $\mathrm{K}$, Erdal $\mathrm{H}$, Hägg $\mathrm{M}$ et al. A novel assay for discovery and characterization of pro-apoptotic drugs and for monitoring apoptosis in patient sera. Apoptosis 8, 263-268 (2003).

8 Wieckowska A, McCullough AJ, Feldstein AE. Noninvasive diagnosis and monitoring of nonalcoholic steatohepatitis: present and future. Hepatology 46, 582-589 (2007).
9 McPartland JL, Guzail MA, Kendall CH, Pringle JH. Apoptosis in chronic viral hepatitis parallels histological activity: an immunohistochemical investigation using anti-activated caspase-3 and M30 cytodeath antibody. Int. J. Exp. Pathol. 86, 19-24 (2005).

10 Fischer U, Jänicke RU, Schulze-Osthoff K. Many cuts to ruin: a comprehensive update of caspase substrates. Cell Death Differ. 10(1), 76-100 (2003).

11 Feldstein AE, Gores GJ. Apoptosis in alcoholic and nonalcoholic steatohepatitis. Front. Biosci. 10, 3093-3099 (2005).

12 Feldstein AE, Canbay A, Guicciardi ME, Higuchi H, Bronk SF, Gores GJ. Diet 
associated hepatic steatosis sensitizes to Fas mediated liver injury in mice. J. Hepatol. 39(6), 978-983 (2003).

13 Day CP, Saksena S. Non-alcoholic steatohepatitis: definitions and pathogenesis. J. Gastroenterol. Hepatol. 17, S377-S384 (2002).

14 Grütter MG. Caspases: key players in programmed cell death. Curr. Opin. Struct. Biol. 10, 649-655 (2000).
15 Stennicke HR, Jürgensmeier JM, Shin $\mathrm{H}$ et al. Pro-caspase-3 is a major physiologic target of caspase-8. J. Biol. Chem. 273, 27084-27090 (1998).

16 Yilmaz Y, Ulukaya E. Toward a biochemical diagnosis of NASH: insights from pathophysiology for distinguishing simple steatosis from steatohepatitis. Curr. Med. Chem. 18(5), 725-732 (2011).
17 Tarantino G, Conca P, Coppola A, Vecchione R, Di Minno G. Serum concentrations of the tissue polypeptide specific antigen in patients suffering from non-alcoholic steatohepatitis. Eur. J. Clin. Invest. 37(1), 48-53 (2007).

18 Tarantino G, Mazzarella C, Tarantino M, Di Minno MN, Conca P. Could high levels of tissue polypeptide specific antigen, a marker of apoptosis detected in nonalcoholic steatohepatitis, improve after weight loss? Dis. Markers 26(2), 55-63 (2009). 